\title{
BMJ Open Utility of the COM-B model in identifying facilitators and barriers to maintaining a healthy postnatal lifestyle following a diagnosis of gestational diabetes: a qualitative study
}

Jennifer Boyd, ${ }^{1}$ Brian McMillan (D) , ${ }^{2}$ Katherine Easton, ${ }^{3}$ Brigitte Delaney, ${ }^{4}$ Caroline Mitchell $^{4}$

To cite: Boyd J, McMillan B, Easton $\mathrm{K}$, et al. Utility of the COM-B model in identifying facilitators and barriers to maintaining a healthy postnatal lifestyle following a diagnosis of gestational diabetes: a qualitative study. BMJ Open 2020;10:e037318. doi:10.1136/ bmjopen-2020-037318

- Prepublication history and additional material for this paper are available online. To view these files, please visit the journal online (http://dx.doi. org/10.1136/bmjopen-2020037318).

Received 28 January 2020 Revised 03 June 2020 Accepted 23 June 2020

\section{Check for updates}

(c) Author(s) (or their employer(s)) 2020. Re-use permitted under CC BY-NC. No commercial re-use. See rights and permissions. Published by BMJ.

${ }^{1}$ School of Health and Related Research, The University of Sheffield, Sheffield, UK ${ }^{2}$ Centre for Primary Care and Health Services Research, The University of Manchester, Manchester, UK

${ }^{3}$ School of Education, University of Sheffield, Sheffield, UK

${ }^{4}$ Academic Unit of Primary Medical Care, The University of Sheffield, Sheffield, UK

\section{Correspondence to} Dr Brian McMillan; brian.mcmillan@manchester. ac.uk

\section{ABSTRACT}

Objectives Previous qualitative research investigating the experiences of women diagnosed with gestational diabetes (GD) has provided important insights into the development of behaviour change interventions. However, these studies often lack a theoretical underpinning. This study explored the use of the capability, opportunity, motivation and behaviour (COM-B) framework (which proposes that individuals need the capability, opportunity and motivation to perform a particular behaviour) to code and the socioecological model to contextualise participant responses to better inform intervention development.

Design Qualitative semistructured interviews are using purposive sampling. Interviews were audio-recorded, transcribed and coded using the COM-B framework. A socioecological approach was adopted to understand the context of intervention facets.

Setting Interviews were conducted in a secondary care setting in South Yorkshire.

Participants Twenty-seven postnatal women with a previous diagnosis of GD were interviewed.

Results Applying the COM-B framework to code participant, responses identified 16 key subthemes which reflected either: capability, opportunity or motivation components of the model. Four domains adapted from the socioecological model: individual, family life, community and healthcare provision; contextualised factors are important for these women in terms of behaviour change. Emotional response at the individual level was highly motivating or demotivating. Factors related to family life and community were particularly dominant and had the potential to either facilitate or impede change. We found many participants relied on healthcare provision during the prenatal and postnatal periods with timing and positive relationships being key to good care.

Conclusions Our study provides further insight into the factors crucial for behaviour change in women diagnosed with GD. By innovatively applying the COM-B framework in a socioecological context, it is clear intervention facets need to target microlevel through the macrolevel to engage this population in behaviour change. Future work should consider family-level intervention as this could allow for sustained behaviour

\section{Strengths and limitations of this study}

- This is the first qualitative study to apply the capability, opportunity, motivation and behaviour framework to understand the experiences of women diagnosed with gestational diabetes (GD).

- Employing a theoretical underpinning from the behaviour change literature provided a depth of insight into which factors should be targeted to improve outcomes for women diagnosed with GD and how these fit within intervention development.

- The use of the socioecological approach allowed for additional specificity regarding the application of intervention facets from the microlevel to macrolevel.

- The sample was exclusively postnatal women with a diagnosis of GD, inclusion of healthcare professionals and policymakers may provide a broader overview required for intervention development.

change and consequently prevent the development of type 2 diabetes mellitus.

\section{INTRODUCTION}

Gestational diabetes (GD) is defined as glucose intolerance which first occurs during pregnancy. ${ }^{1}$ Almost 1 in 20 pregnant women in the UK develops GD and prevalence is increasing. ${ }^{2}$ Having had GD doubles, the risk of subsequently developing type 2 diabetes mellitus (T2DM) up to 4 months postnatally, ${ }^{3}$ and women who have had GD are over seven times more likely to be diagnosed with T2DM in their lifetime. ${ }^{4}$ The adverse health outcomes associated with T2DM are well documented and include a reduction in average life expectancy by 10 years. ${ }^{5}$ In addition, children born to a mother with GD have an increased risk of developing obesity, T2DM and cardiovascular disease. 6 
In the UK, women diagnosed with GD receive additional antenatal specialist care to reduce the risk of adverse materno-fetal outcomes, including advice aimed at increasing physical activity and promoting a healthy diet. The National Institute for Health and Care Excellence (NICE) guidance to support women with GD is well adhered to antenatally in secondary care. ${ }^{7}$ Although women with GD are generally satisfied with the care they receive antenatally, many feel abandoned postnatally and are uncertain about what to expect from their general practitioner (GP) regarding support and follow-up. ${ }^{8}$ Given the pressures on primary care in terms of a declining workforce, increasing workload and constraints on funding, ${ }^{9}$ we need to develop innovative postnatal interventions to reduce the risk of T2DM among women who have had GD.

Qualitative studies of women's experiences of GD and the care they receive have identified important issues to address. ${ }^{8} 10^{11}$ Although women diagnosed with GD are aware, it increases their risk of developing T2DM, ${ }^{12}$ they find acting on this knowledge difficult and have difficulty recalling long-term lifestyle recommendations ${ }^{13}$ and the motivation to make lifestyle changes during pregnancy often dissipates postnatally. ${ }^{8}$ Women report that barriers to a healthy lifestyle postnatally include fatigue, lack of resources, financial constraints and competing demands on their time, and facilitators include personal preferences, weaning and provision of longer term support. ${ }^{811} 12$ Several behaviour change interventions (BCIs) have targeted the risk of progression from GD to T2DM, but only two randomised controlled trials (RCTs) have demonstrated significant effects, and these were intensive interventions that would be difficult to deliver in a community setting. ${ }^{145}$ An ongoing UK-based RCT similarly incorporates a group education programme in a secondary care setting, although this is being supplemented with a digital component. ${ }^{16}$

Interventions aimed at reducing progression from GD to T2DM to date have lacked a strong theoretical grounding in behaviour change theory. The Behaviour Change Wheel $(\mathrm{BCW})^{17}$ offers a comprehensive tool for intervention development. It consists of three layers (figure 1). At the

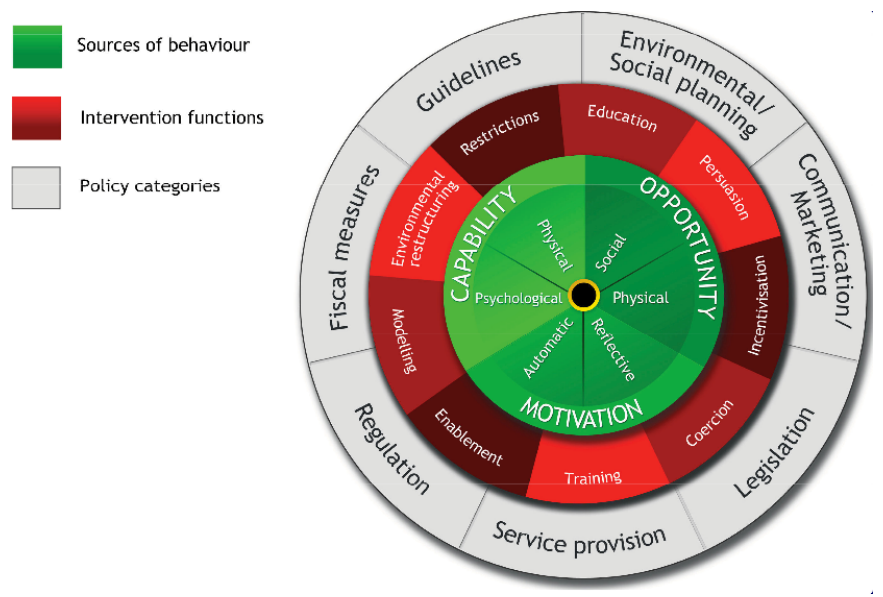

Figure 1 The Behaviour Change Wheel. Figure used with permission from Michie et al. ${ }^{17}$ centre of the wheel is the capability, opportunity, motivation and behaviour (COM-B) model, which identifies sources of behaviour to be targeted by interventions. These include 'capability' (physical and psychological), 'opportunity' (physical and social) and 'motivation' (automatic and reflective). ${ }^{17}$ The layers surrounding the COM-B model are nine intervention functions which can be used to address the corresponding sources of behaviour; capability, opportunity or motivation. Finally, the outer layer identifies seven policy functions which can be used to deliver interventions.

To reduce the risk of progression from GD to T2DM, we need an affordable BCI, grounded in behaviour change theory, which can be delivered in the primary care setting postnatally. Such an intervention needs to enable a sustained change in diet and exercise and be acceptable and accessible to women in their own communities. ${ }^{8}$ As far as the authors are aware, there has been no work to date combining qualitative data with an established behaviour change framework $^{17}$ in order to develop recommendations for a BCI aimed at reducing the risk of progression from GD to T2DM. Therefore, this qualitative study aims to map themes identified from interviews with women who have had GD on to the COM-B model and use the broader BCW framework to suggest future areas for interventions aimed at this population. To better understand where to apply the intervention facets, a socioecological approach was also taken. ${ }^{18}$

\section{METHODS}

We conducted semistructured interviews between 6 and 12 weeks postnatally with women previously diagnosed with GD (see online supplementary appendix 1 for study protocol and online supplementary appendix 2 for interview schedule). A qualitative approach was taken as it best captures women's personal accounts of their care, the associated psychological and physical impacts of such care and the way in which they attribute meaning to their health behaviours. ${ }^{19}$ We used the Standards for Reporting Qualitative Research (SRQR) checklist when writing our report. ${ }^{20}$

\section{Sampling and recruitment}

The research was conducted at Sheffield University Teaching Hospital National Health Service (NHS) Foundation Trust, between February 2016 and January 2017. Participants were women aged over 16 years who had received a diagnosis of GD in the preceding 6 months. Women who had suffered a miscarriage or stillbirth were excluded. Invitations to participate were sent out along with appointment letters for a routine postnatal oral glucose tolerance test (OGTT). In line with Braun and Clarke ${ }^{21}$ who argue in favour of transferability rather than generalisability in qualitative research, we employed a purposive approach to achieve a maximum-variety sample (age, parity, socioeconomic status and ethnicity). In addition, OGTT nonattenders were targeted by sending further study invitations offering a home visit or telephone interview. All the women we invited to take part in the study agreed to participate. 


\section{Data collection methods}

A semistructured topic guide was developed following preparatory work. This included attendance at a mother and toddler group, observation of antenatal education sessions, feedback from a patient and public involvement (PPI) exercise ${ }^{22}$ and discussions with an expert steering group. The interview schedule contained demographic and clinical questions as well as questions and prompts to explore women's experiences of care, pre and postnatally. Further to this, women were asked about barriers and facilitators to healthy lifestyle behaviours such as diet, exercise and weight management. Informed consent was obtained from all participants before the interviews were conducted. Interviews were recorded on an encrypted digital recorder and transferred to a password protected, secure university database.

\section{Data analysis}

The two interviewers (BM and BD) made contemporaneous field notes on the interviews and data were transcribed verbatim. These transcripts and notes were imported into NVivo (V.11). A seven-stage approach to analysis was implemented $^{21}$; data familiarisation, coding using the COM-B model,${ }^{17}$ identification of subthemes within the framework, review and revision of subthemes, definition and naming of subthemes, analysis and interpretation of patterns across the data and amalgamation of subthemes into dominant contextual domains. To understand contextual domains, a socioecological approach to health was taken. ${ }^{18}$ The interview transcripts were coded and initially analysed by an independent researcher (JB), however, all coauthors contributed to the final analysis. At each stage of the process, discussions among the team ensured consistency and helped identify the key issues.

\section{Patient and public involvement}

Patients and the public were involved in the design and conduct of the study. A full description of this PPI work has been published elsewhere ${ }^{22}$ and describes when and how patients were involved, how the research questions were developed and informed by their priorities, experience and preferences. This published PPI report also details how we planned to involve patients and the public in disseminating study results to participants and linked communities.

\section{RESULTS/FINDINGS \\ Demographics}

Twenty-seven women were interviewed (mean age $=33$ years, range 22-44). Most participants were married, white, had previous family history of T2DM and had completed education up to degree level. Table 1 highlights the demographic characteristics of the study sample.

\section{Key themes identified and their relevant domains}

The initial coding framework was comprised of 3 superordinate themes, 6 subordinate themes and 16 subthemes (table 2). Four dominant domains were identified from the 16 subthemes: individual, family life, community and

\begin{tabular}{|c|c|c|}
\hline Characteristics & $\mathbf{N}$ & $\%$ \\
\hline \multicolumn{3}{|l|}{ Marital status } \\
\hline Married & 20 & 74.1 \\
\hline Cohabiting & 7 & 25.9 \\
\hline \multicolumn{3}{|l|}{ Ethnicity } \\
\hline White & 20 & 74.1 \\
\hline Asian & 3 & 11.1 \\
\hline Black African & 1 & 3.7 \\
\hline Arab & 3 & 11.1 \\
\hline \multicolumn{3}{|l|}{ Education } \\
\hline Degree level & 18 & 66.7 \\
\hline Further education & 3 & 11.1 \\
\hline School to 16 years & 3 & 11.1 \\
\hline School to $\leq 16$ years & 3 & 11.1 \\
\hline \multicolumn{3}{|l|}{ Occupation } \\
\hline Professional & 10 & 37.0 \\
\hline Sales/customer service & 5 & 18.5 \\
\hline Caring/leisure/other & 4 & 14.8 \\
\hline Admin/secretarial & 2 & 7.4 \\
\hline Associate/technical & 2 & 7.4 \\
\hline Self-employed & 1 & 3.7 \\
\hline Not working & 3 & 11.1 \\
\hline \multicolumn{3}{|l|}{ Diabetes history } \\
\hline Family history of T2DM & 21 & 77.8 \\
\hline Previous GD & 4 & 14.8 \\
\hline \multicolumn{3}{|l|}{ Previous pregnancies } \\
\hline 0 & 10 & 37.0 \\
\hline 1 & 11 & 40.7 \\
\hline 2 & 5 & 18.5 \\
\hline$\geq 3$ & 1 & 3.7 \\
\hline
\end{tabular}

GD, gestational diabetes; T2DM, type 2 diabetes mellitus.

healthcare provision. The four domains reflected the structure of a socioecological model of health ${ }^{18}$ identifying areas from the microlevel to macrolevel which need to be targeted to create and sustain behaviour change. Three of the initial 16 subthemes were not categorised into the contextual domains as they were not deemed amenable to intervention. Figure 2 demonstrates the relationship between domains and subthemes.

\section{Individual}

The individual contextual domain reflects issues at the microlevel which women with GD deemed important for behaviour change. These focused mainly on the motivational components; both automatic and reflective, however, indicated an interaction with motivation and psychological capabilities.

\section{Emotions}

A prominent theme was emotional response to diagnosis. Many indicated initial shock at diagnosis. The 


\begin{tabular}{|c|c|c|c|c|}
\hline COM-B & Framework & Subtheme & Concepts & Contextual domain \\
\hline \multirow[t]{5}{*}{ Capability } & \multirow[t]{3}{*}{ Psychological } & Knowledge & Lack of knowledge, acquisition, resources & $\begin{array}{l}\text { Healthcare provision/ } \\
\text { community }\end{array}$ \\
\hline & & $\begin{array}{l}\text { Cognitive } \\
\text { difficulties }\end{array}$ & Denial, memory, language barriers, inability to focus & Healthcare provision \\
\hline & & $\begin{array}{l}\text { Previous } \\
\text { experience }\end{array}$ & Family history, previous diagnosis & Family life \\
\hline & \multirow[t]{2}{*}{ Physical } & Existing capacity & Predisposition to exercise or not & * \\
\hline & & Physical restriction & $\begin{array}{l}\text { Medical conditions, overweight, mobility, postnatal complications, } \\
\text { fatigue }\end{array}$ & * \\
\hline \multirow[t]{6}{*}{ Opportunity } & \multirow[t]{2}{*}{ Social } & Influence of family & $\begin{array}{l}\text { Childcare support, encouragement, advice, isolation, negative } \\
\text { influence, mealtimes }\end{array}$ & Family life \\
\hline & & Social belonging & Peer support groups, virtual support, socialising while exercising & Community \\
\hline & Social/physical & $\begin{array}{l}\text { Competing } \\
\text { priorities }\end{array}$ & Time restrictions, family first, self-neglect & Family life \\
\hline & \multirow[t]{3}{*}{ Physical } & $\begin{array}{l}\text { Healthcare } \\
\text { environment }\end{array}$ & $\begin{array}{l}\text { Importance of primary/secondary care, issues of availability, } \\
\text { healthcare process, negative interactions with staff }\end{array}$ & Healthcare provision \\
\hline & & Convenience & $\begin{array}{l}\text { Community resources, work/other duties incorporate exercise, } \\
\text { availability of apps }\end{array}$ & Community \\
\hline & & Financial & Affordability, subsidies & * \\
\hline \multirow[t]{5}{*}{ Motivation } & \multirow[t]{3}{*}{ Reflective } & Plans & Creating solid plans to promote behaviour change & Individual \\
\hline & & Intentions & Indenting to change behaviour & Individual \\
\hline & & Monitoring & $\begin{array}{l}\text { Tracking behaviour, positive reinforcement, diet restriction, goal } \\
\text { setting }\end{array}$ & Individual \\
\hline & \multirow[t]{2}{*}{ Automatic } & Emotions & Anxiety, overwhelmed, shock, worry, concern, depression & Individual \\
\hline & & Disengaged & Postponement, dislike, denial & Individual \\
\hline
\end{tabular}

*Subthemes not categorised into a contextual domain.

COM-B, capability, opportunity, motivation and behaviour.

associated emotions were expressed as either a mechanism to encourage behaviour change or as a barrier to behaviour change. Some felt worried or concerned about their health given the diagnosis and therefore felt the need to change.

still concerns me so I'm trying to lose weight now and every time I get demotivated, I just think about that

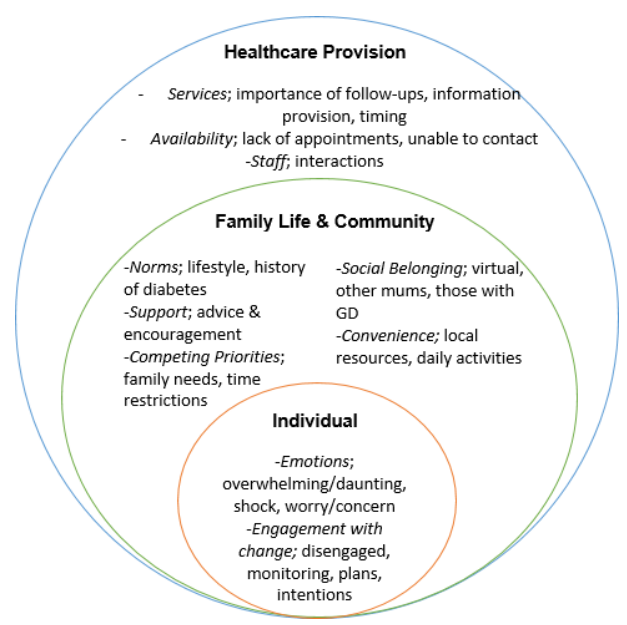

Figure 2 How do the contextual domains and subthemes important to women with GD fit within the socioecological model (adapted from Dahlgreen and Whitehead ${ }^{18}$ ). GD, gestational diabetes. increased risk and it is a really good spur. (P2, aged 37)

Others felt completely overwhelmed by their new diagnosis and this often led had an emotional toll which made it difficult to engage in behaviour change.

So, the first shock is when I actually got the letter, I was really, really shocked and it affected me quite a bit, I was quite depressed for a couple of days. (P25, aged 38)

\section{Engagement with change}

The other dimension in the individual context was how they engaged in behaviour change. Those that did choose to engage emphasised the use of monitoring, plans and intentions. Many women spoke of their plans and intentions to incorporate diet and exercise into their lifestyle in a variety of ways. Those who engaged in change often mentioned the use of apps or manual recording as motivation for continuing with healthy behaviours.

I used My Fitness Pal on the phone. I love it, I used to use it before I was pregnant just to register religiously put down everything I'd eaten, and it tracks how far I've walked every day as well. (P8, aged 28)

Conversely, there were a proportion of participants who expressed they did not engage in behaviour change. 
Participants did not want to engage if there was a restriction in life for example, work getting in the way or because simply, they do not like exercising, eating healthy or using apps/trackers.

I don't like to be told that I can't eat anything but that's a bit of a worry, especially when it's cake and chocolate. (P22, aged 35)

\section{Family Life}

Family and the wider community were two domains which captured concerns surrounding behaviour change at the mesolevel. These domains consisted of opportunity components; social and physical.

\section{Norms}

Women indicated that a major influence of behaviour change was their family environment. One reoccurring theme was the presence of norms which were either positively or negatively associated with the adoption of a healthy lifestyle. Many women felt that norms within their close family network facilitated or hindered positive behaviour change. There was a focus on partners' behaviour and how that influenced their own both positively and negatively.

Bad influences. Like my partner, he has sweets and biscuits 'cause he's got a really sweet tooth, so if I see him eating it, it makes me want it. (P12, aged 22)

Another specific issue of contention within the family household was mealtimes. Women felt changing their diet was extremely difficult as it went against the norm of family meals; sitting down and eating the same thing at the dinner table. Many indicated diet change produced difficulties with preparation and consequently reduced the enjoyment of mealtimes.

It's difficult because you can't eat with your family at the same time, sometimes it's different food. I like, I have kids and I have to cook for him, so I have to cook for him, I have to cook for myself... everything is not like the same at all. (P21, aged 29)

Not only did norms have an impact of lifestyle directly but many women indicated that if there was a family history of diabetes or previous diagnosis, they felt more aware of the consequences of their condition.

the family history, because I know it's there, I could develop it at any point of my life. (P25, aged 38)

\section{Support}

A prominent theme within the family life context was the level of support women received from their family and close friends. One facet of this support was in the form of advice and encouragement which aided behaviour change. This tended to be in the context of practical tips on how to become more active or eat healthier.

one of my friends recommended something to me to make it easier, she started wearing a sling in the house so that then that way you could-, you have the time to be preparing healthier dinners... people said 'well have you thought about trying this because it might help you in the long run with the losing weight and the diabetes. (P11, aged 32)

The other facet of family support was linked to a strong family presence. This was in relation to providing practical support by helping with childcare and other household duties. Many women emphasised the importance of help from their families to relieve them of all the childcare and household duties which would then free up their time to engage in exercise or preparing healthy meals.

Being able to actually arrange my time around my little girl now it's going to be quite a crucial one. Being able to hand her to partner or make sure he's going to be in... Having my parents on standby perhaps might be a good one. (P17, aged 37)

This seemed to be a key issue for some women who did not have family living nearby and therefore felt isolated which provided a barrier to behaviour change.

we don't have any of our family nearby. So, I think you know if you don't have that support network, do a bit of babysitting, go out on your own. (P18, aged 34)

\section{Competing priorities}

This idea of support or a lack thereof additionally represents the sense of competing priorities. The prioritisation of family tasks such as household duties and childcare was a reoccurring issue for these women. Many indicated they postponed positive behaviours such as exercise due to this prioritisation.

I mean one of my favourite things to do is swim and getting out to go swimming is tricky. Because of what time is somebody looking after the kids. (P19, aged 44)

The women expressed they felt they had no time to prepare healthy meals or exercise. This lack of time was often reflected in the neglecting of personal needs, by prioritising other duties.

I have a lot of duties in my home so I'm sometimes actually I have to-, I cannot find the time for myself, so I have to do organise, reorganise everything in my life. (P7, aged 39)

\section{Community}

\section{Social belonging}

The notion of social connection was not isolated to the family context but also mentioned in a community setting. For many women, a sense of social belonging or shared identity was important when attempting behaviour change. One prominent theme was social belonging on a virtual plane. Women often expressed the use of online forums for seeking relevant information or developing social relations with people experiencing the same thing. 
they've got like community forums linked with them I'd check on there and they had a bit more information and a gestational diabetes help group on Facebook I actually make a friend from joining that as well and we're still friends now. (P20, aged 28)

Not only was this expressed in the virtual domain, the women repeatedly referred to face-to-face interactions with people in similar circumstances. One particularly popular suggestion was the creation of exercise or support groups for mums, particularly those who had GD, in the community.

if there was a baby group that you could go to where other mothers had this increased risk you could have more contact with people that are in the same boat... were trying to struggle with the same things that you were...maybe you could all go and walk together. (P2, aged 37)

\section{Convenience}

Another prominent theme that fell within the context of community was convenience. These women expressed it was easier to engage in behaviour change if the opportunity to do so was easily accessible to them. One form of convenience was the resource available to them in their locality. Many indicated the importance of local baby groups, workshops or leisure facilities.

maybe have like a morning for or afternoon for like pregnant women or something to say well look your local leisure centre. (P8, aged 28)

Convenience also aided behaviour change if changes could be easily incorporated into daily activities. Everyday rituals such as commuting, work, household duties or taking children to school were all excellent opportunities to become more active.

I take me son to nursery every morning. I walk there and walk back. I go shopping sometimes. I walk to shops. (P14, aged 28)

\section{Healthcare provision}

The women interviewed in this study highlighted the crucial role of healthcare provision in creating and sustaining behaviour change. This macrolevel domain captured the ability of healthcare to provide physical opportunities and build psychological capability.

\section{Services and availability}

The healthcare environment was also central to facilitate behaviour change. One reoccurring theme was the presence and availability of healthcare services in relation to their diagnosis and support in managing GD. An initial concern for some participants was timing. Many found it difficult to digest information when given immediately following diagnosis or birth of the child which created a barrier to sustained behaviour change. Relatedly, regular follow-ups following diagnosis were considered valuable and necessary.

I think it'd be better off after the sixweeks check, so like sixweeks, maybe your baby's still getting up during the night, so you are still a bit flustered and tired. (P12, aged 22)

Another important facet of information provision was the healthcare practitioner relationship as a source of quality advice and support. For many women their GP, nurse or healthcare visitor was frontline support to managing GD and engaging in behaviour change.

you could discuss if there was anything that you'd had that you were concerned about... they'd be able to tell you why and what sort of things you needed to change and so I found them really helpful. (P11, aged 32)

One negative component of healthcare services was a lack of availability of appointments or resources. Many indicated frustration associated with attempts to contact and make appointment with GP surgeries, which they felt was a barrier to the care they required.

you try and phone up for an appointment and you can't get in for about three, four, five weeks at a time that's how bad it is. And you're phoning up all the time and you can't get through. (P5, aged 22)

\section{Interactions}

Another negative aspect of the healthcare environment included negative interactions with healthcare staff. These negative interactions highlight potential difficulties women with GD face in accessing the support and resources provided in the healthcare sector. Therefore, feelings of judgement may provide a barrier to behaviour change for these women.

they can start treating patients with a bit more respect at our doctors... Receptionist are terrible on the phone, they terrible. They give you a load of verbal. (P14, aged 28)

\section{DISCUSSION}

We believe this is the first study to use the COM-B framework to code and analyse qualitative responses from women diagnosed with GD. The purpose of this was to ensure findings were grounded in theory and to efficiently identify the key components of an intervention which could create and sustain behaviour change. Initial coding revealed 16 subthemes which fit into the capability, opportunity and motivation components of the model. To better understand the role of these subthemes in the context of intervention development, they were categorised into four contextual domains: individual, family life, community and healthcare provision. 


\section{Individual}

One important facet was the automatic motivation to adopt healthier behaviours triggered or inhibited by emotional response to diagnosis. The other was reflective motivation which successfully implemented behaviour change in women who used monitoring, plans and intentions to engage with behaviour change. However, a proportion of women were also demotivated by reflective processes if they disliked aspects of the behaviour change or due to restrictions in life.

\section{Family life and community}

Family was of critical importance and either negated or facilitated positive behaviour change via several mechanisms. Family norms surrounding lifestyle and a history of diabetes, practical and emotional support and the notion of competing priorities were crucial to the ability to engage in change. The wider community was also a factor in terms of social belonging with many suggesting the creation of opportunities to engage in activities alongside other mums, friends or others diagnosed with GD. Additionally, convenience offered the physical opportunity to easily integrate new behaviours into their pre-existing routine.

\section{Healthcare provision}

Many of the women highlighted the importance of readily available services to provide information on the condition and advice to support behaviour change. A critical facet was the timing of service provision and the need for follow-ups to ensure that behaviour change was maintained and future concerns were addressed. The relationship with healthcare staff was also crucial as positive relations were a facilitator of change, while negative interactions provided a barrier.

\section{Comparison with existing literature}

The findings complement and enhance the existing qualitative work in this area. The experience of shock and the need for an adjustment period after diagnosis have been highlighted in the previous research. ${ }^{23}$ The theme of competing priorities, particularly the prioritisation of family needs above their own needs, is also well documented. ${ }^{824}$ Certainly, healthcare provision, particularly the availability of follow-ups postpartum and a cohesive positive relationship with clinicians, is a well-established concern for women diagnosed with GD. ${ }^{25}$ The findings of this study also closely align with a meta-synthesis conducted to explore the factors required in the development of an intervention to prevent T2DM in this population which also found that addressing emotions, the timing of information and engaging at a family level were promising directions for intervention. ${ }^{26}$ However, this study provides additional insight into the necessary facets, an intervention must possess to create and sustain change in this population. It is clear from the results that a successful intervention must tackle wider contextual factors not just individual-level behaviours which fit with the existing NICE guidance on preventing T2DM using population-level and community-level approaches. ${ }^{27}$
The development of an appropriate intervention would require input from primary healthcare services which are the frontline resources for women diagnosed with GD. A wider approach is also required, intervening at the familial level rather than the individual, as family needs and norms are critical to sustaining behaviour change. Previous works reviewing the efficacy of family interventions demonstrate improved patient outcomes for several conditions, including diabetes. ${ }^{28}{ }^{29}$ Mapping from the BCW, there are several intervention functions which could be mobilised. However, engaging in education, persuasion and training facets at the familial level rather than the individual could provide a cost-effective solution which would not only improve the health of those with GD but also their families.

\section{Limitations}

One limitation of this study is that only women with GD were interviewed. To address this, future studies should investigate the views of family members, healthcare staff and public health policymakers to provide a broader perspective for intervention development. However, focusing on the women's experiences in the first instance has generated valuable insights into frame future research.

Additionally, the development of four contextual domains focused on the subthemes believed to be easily amenable to intervention. Thus, not all factors were fully discussed. The researchers were transparent regarding the translation of subthemes to contextual domains.

Limitations regarding study design included conducting interviews soon after the women gave birth. This may influence the responses provided as given a longer time frame, there may be other important factors for creating and sustaining behaviour change. However, it is also important to capture the early postnatal period, which is a key time to intervene while the women are in regular contact with healthcare providers.

Although over a quarter of our sample was non-white, and we did identify some issues specific to ethnicity and culture within our data, it is possible we did miss some cultural issues important within other ethnicities. Future work could build on our findings and previous work ${ }^{13}$ to further explore cultural differences among women who have had GD, and how these might inform future interventions.

Finally, it is possible that the backgrounds of the researchers impacted the dynamic of the interviews. The influence of this on findings was minimised by involving an independent researcher who coded and analysed responses with input from the wider team.

\section{CONCLUSIONS}

This study provides new insight into factors important for creating and sustaining behaviour change in women diagnosed with GD. The novel use of the COM-B framework when applied in a socioecological context has identified the complexities inherent in intervention development requiring the targeting of micro, meso and macrolevels 
to prove effective in this population. Successful behaviour change relies on context, and for women with GD, a familyoriented approach was of importance. Future research aiming to develop a BCI for this group should engage family members in intervention design and consider tackling families rather than individuals in isolation. This could be key to sustaining behaviours which prevent the development of T2DM.

Twitter Jennifer Boyd @jenniferevab, Brian McMillan @brwmcmillan and Caroline Mitchell @dclovesGP

Contributors BM and CM designed the study, obtained funding, developed and refined the study protocol. BM and BD undertook data collection. JB undertook analysis and interpretation with contributions from all coauthors. All coauthors (BM, $\mathrm{CM}, \mathrm{JB}, \mathrm{BD}$ and $\mathrm{KE}$ ) prepared the manuscript. All authors read and approved the final manuscript.

Funding This work was supported by the Royal College of General Practitioners Scientific Foundation Board, grant number SFB 2015-04. The interviews were completed while BM was employed as a National Institute for Health Research (NIHR) Academic Clinical Fellow (award reference: 1897). The views expressed are those of the authors and not necessarily those of the NHS, the NIHR or the Department of Health.

Competing interests None declared.

Patient and public involvement Patients and/or the public were involved in the design, or conduct, or reporting, or dissemination plans of this research. Refer to the Methods section for further details.

\section{Patient consent for publication Not required.}

Ethics approval NHS Health Research Authority approval was provided through Integrated Research Application System (IRAS) submission (project ID: 192921) and ethical approval was granted by the Wales Research Ethics Committee 7 (REC reference 16/WA/0084). NHS permission for research to commence was granted by the Sheffield University Teaching Hospital NHS Foundation Trust (SUHT) (reference: STH19316)

Provenance and peer review Not commissioned; externally peer reviewed.

Data availability statement № data are available. not applicable.

Open access This is an open access article distributed in accordance with the Creative Commons Attribution Non Commercial (CC BY-NC 4.0) license, which permits others to distribute, remix, adapt, build upon this work non-commercially, and license their derivative works on different terms, provided the original work is properly cited, appropriate credit is given, any changes made indicated, and the use is non-commercial. See: http://creativecommons.org/licenses/by-nc/4.0/.

ORCID iD

Brian McMillan http://orcid.org/0000-0002-0683-3877

\section{REFERENCES}

1 World Health Organization. Diagnostic criteria and classification of hyperglycaemia first detected in pregnancy: a world Health organization guideline. Diabetes Res Clin Pract 2014;103:341-63.

2 National Institute for Health and Care Excellence. Diabetes in pregnancy: management from preconception to the postnatal period (NG3). London, 2015. Available: https://www.nice.org.uk/ guidance/ng3/resources/diabetes-in-pregnancy-management-frompreconception-to-the-postnatal-period-pdf-51038446021

3 Ratner RE. Prevention of type 2 diabetes in women with previous gestational diabetes. Diabetes Care 2007;30 Suppl 2:S242-5.

4 Bellamy L, Casas J-P, Hingorani AD, et al. Type 2 diabetes mellitus after gestational diabetes: a systematic review and meta-analysis. Lancet 2009;373:1773-9.

5 Department of Health. A national service framework for diabetes: standards. London, 2001.

6 Dabelea D. The predisposition to obesity and diabetes in offspring of diabetic mothers. Diabetes Care 2007;30 Suppl 2:S169-74.
7 Sukumaran S, Madhuvrata P, Bustani R, et al. Screening, diagnosis and management of gestational diabetes mellitus: a national survey. Obstet Med 2014;7:111-5.

8 McMillan B, Easton K, Goyder E, et al. Reducing risk of type 2 diabetes after gestational diabetes: a qualitative study to explore the potential of technology in primary care. Br J Gen Pract 2018:68:e260-7.

9 Baird B, Charles A, Honeyman M, et al. Understanding pressures in general practice. London, 2016. Available: https://www.kingsfund. org.uk/sites/default/files/field/field_publication_file/UnderstandingGP-pressures-Kings-Fund-May-2016.pdf

10 Chasan-Taber L. Lifestyle interventions to reduce risk of diabetes among women with prior gestational diabetes mellitus. Best Pract Res Clin Obstet Gynaecol 2015;29:110-22.

11 Dennison RA, Ward RJ, Griffin SJ, et al. Women's views on lifestyle changes to reduce the risk of developing type 2 diabetes after gestational diabetes: a systematic review, qualitative synthesis and recommendations for practice. Diabet Med 2019;36:702-17.

12 Morton S, Kirkwood S, Thangaratinam S. Interventions to modify the progression to type 2 diabetes mellitus in women with gestational diabetes: a systematic review of literature. Curr Opin Obstet Gynecol 2014;26:476-86.

13 Zulfiqar T, Lithander FE, Banwell C, et al. Barriers to a healthy lifestyle post gestational-diabetes: an Australian qualitative study. Women Birth 2017;30:319-24.

14 Ratner RE, Christophi CA, Metzger BE, et al. Prevention of diabetes in women with a history of gestational diabetes: effects of metformin and lifestyle interventions. J Clin Endocrinol Metab 2008;93:4774-9.

15 Wein P, Beischer N, Harris C, et al. A trial of simple versus intensified dietary modification for prevention of progression to diabetes mellitus in women with impaired glucose tolerance. Aust N Z J Obstet Gynaecol 1999;39:162-6.

16 Sukumar N, Dallosso H, Saravanan P, et al. Baby steps - a structured group education programme with accompanying mobile web application designed to promote physical activity in women with a history of gestational diabetes: study protocol for a randomised controlled trial. Trials 2018;19:1-12.

17 Michie S, van Stralen MM, West R. The behaviour change wheel: a new method for characterising and designing behaviour change interventions. Implement Sci 2011;6:42.

18 Dahlgren G, Whitehead M. Policies and strategies to promote social equity in health. Background document to WHO - Strategy paper for Europe. Stockholm, 1991. https://core.ac.uk/download/pdf/6472456. pdf

19 Bryman A. Social research methods. 4th ed. Oxford:Oxford University Press, 2012.

20 O'Brien BC, Harris IB, Beckman TJ, et al. Standards for reporting qualitative research: a synthesis of recommendations. Acad Med 2014;89:1245-51.

21 Braun V, Clarke V. Successful qualitative research: A practical guide for beginners. London: Sage, 2013.

22 McMillan B, Easton K, Delaney B, et al. Reducing the risk of progression from Gestational Diabetes to Type 2 Diabetes Mellitus: Women's perspectives on the content, research development and evaluation of a mobile health technology lifestyle intervention to support postnatal dietary and activity. Sheffield 2017.

23 Carolan M. Women's experiences of gestational diabetes selfmanagement: a qualitative study. Midwifery 2013;29:637-45.

24 Lie MLS, Hayes L, Lewis-Barned NJ, et al. Preventing type 2 diabetes after gestational diabetes: women's experiences and implications for diabetes prevention interventions. Diabet Med 2013;30:986-93.

25 Van Ryswyk E, Middleton P, Shute E, et al. Women's views and knowledge regarding healthcare seeking for gestational diabetes in the postpartum period: a systematic review of qualitative/survey studies. Diabetes Res Clin Pract 2015;110:109-22.

26 Parsons J, Ismail K, Amiel S, et al. Perceptions among women with gestational diabetes. Qual Health Res 2014;24:575-85.

27 National Institute of Health and Care Excellence. Type 2 diabetes prevention: population and community-level interventions. London, 2011.

28 Armour TA, Norris SL, Jack L, et al. The effectiveness of family interventions in people with diabetes mellitus: a systematic review. Diabet Med 2005;22:1295-305.

29 Baig AA, Benitez A, Quinn MT, et al. Family interventions to improve diabetes outcomes for adults. Ann N Y Acad Sci 2015;1353:89-112. 